\title{
METODE STIMULASI DAN METODE MODELING TERHADAP CARA MENGGOSOK GIGI YANG BENAR PADA ANAK PRASEKOLAH
}

\author{
Anis Rosatil Jannah*, Husnul Khotimah, Sri Astutik Andayani. Kholisotin, Abdul Hamid \\ Program Studi Keperawatan, Fakultas Kesehatan, Universitas Nurul Jadid, Jl.KH. Zaini Mun'im Karanganyar Paiton \\ Probolinggo, Jawa Timur, Indonesia 67291 \\ *anisrosatil@gmail.com
}

\begin{abstract}
ABSTRAK
Penyakit gigi dapat mempengaruhi kesehatan tubuh, jika dibiarkan akan berdampak pada penyakit yang lebih berbahaya, seperti: serangan jantung, stroke, diabetes, infeksi pernafasan, gastrointestinal dll. Salah satu upaya meningkatkan keterampilan cara menggosok gigi pada anak adalah melalui cara atau metode stimulasi dan modeling. Tujuan penelitian ini adalah untuk mengetahui pengaruh penyuluhan tentang kebersihan gigi dan mulut melalui metode stimulasi dan modeling terhadap cara menggosok gigi yang benar pada anak prasekolah di TK Bina Ana Prasa. Desain Penelitian ini yaitu Quasi Eksperimen dengan pendekatan two group pre-post test design dengan jumlah sampel yaitu 80 orang, untuk metode stimulasi sebanyak 40 responden dan untuk metode modeling sebanyak 40 responden dengan menggunakan Purposive Sampling. Teknik pengumpulan data menggunakan lembar observasi. Analisa data menggunakan uji statistik Uji Wilcoxon dan Mann-Whitney. Uji Wilcoxon pada kelompok stimulasi didapatkan nilai $\rho=0,000$. Sedangkan pada kelompok modeling didapatkan nilai nilai $\rho=0,000$. Dan untuk membandingkan kelompok stimulasi dan modeling menggunakan Uji Mann-Whitney dengan hasil $\rho=0,000$, Jadi dapat disimpulkan bahwa dengan metode stimulasi dan modeling dapat meningkatkan perilaku dan keterampilan anak untuk menggosok gigi yang benar. Dan dari hasil observasi stimulasi dan modeling itu lebih efektif yang modeling.
\end{abstract}

Kata kunci: modeling, enggosok gigi, stimulasi

\section{METHOD OF STIMULATION AND MODELING METHOD OF HOW TO SCROLT THE CORRECT DENTAL IN PRESCHOOL CHILDREN}

\begin{abstract}
Dental diseases can affect the health of the body, if left unchecked it will have an impact on more dangerous diseases, such as: heart attack, stroke, diabetes, respiratory infections, gastrointestinal etc. The purpose of this research is to determine the effect of dental and oral hygine counselling throungh stimulation and modelling methods toward how to brush teeth properly in preschool children at TK Bina Ana Prasa. The design of this research is quasi eksperiment with a two group pre-post test design approach with sample size of 80 people, for stimulation methods for about 40 respondents and for the modelling method as many as 40 respondents using purposive sampling. Data collection techniques use observation sheets. using wilcoxon and mann-whitney test statistics. The data analysis used was wilcoxon test in the stimulation group obtained $p$ value $=0,000$. while in the modelling group the value $p=0,000$. And to compare stimulation and modelling group using the mann-whitney test with the result of $p=0,000$, So it can be concluded that stimulation and modeling methods can improve children's behavior and skills to brush their teeth properly. And from the results of observation of stimulation and modeling it is more effective modeling.
\end{abstract}

Keywords: modeling, brush teeth, stimulation

\section{PENDAHULUAN}

Penyakit gigi dapat mempengaruhi kesehatan tubuh, jika dibiarkan akan berdampak pada penyakit yang lebih berbahaya, seperti: serangan jantung, stroke, diabetes, infeksi pernafasan, gastrointestinal dll (Larasati, 2013). Kerusakan gigi pada usia dini dapat memengaruhi pertumbuhan gigi (Roosihermiatie, Tumaji, \& Oktarina, 2016). Fungsi gigi sangat diperlukan dalam masa kanak-kanak yaitu sebagai alat pengunyah, membantu dalam berbicara, keseimbangan wajah, penunjang estetika wajah anak. Jika anak tidak bisa mengunyah dengan baik maka nanti akan terjadi malnutsi, dan proses belajarnya akan terganggu (Triska, Damajanti, 2014).

Pembelajaran dengan cara menggosok gigi yang baik dan benar pada anak prasekolah adalah metode stimulasi dan teknik modeling. Stimulasi anak usia dini adalah kegiatan merangsang secara 
memadai kemampuan dasar anak agar tumbuh dan berkembang optimal sesuai potensi yang di miliki oleh anak, Membantu perkembangan dalam sensorik dan motoriknya. Sedangkan teknik modeling adalah suatu komponen dari suatu strategi dimana konselor menyediakan demonstrasi tentang tingkah laku yang menjadi tujuan. Dengan metode stimulasi dan modeling anak dapat memperagakan langsung dengan sikap dan tingkah laku yang benar (Asrianti, Tahir, \& Barasandji, 2014).

Kesehatan gigi dan mulut merupakan bagian dari kesehatan tubuh seseorang secara keseluruhan. Kesehatan gigi dan mulut masyarakat Indonesia masih merupakan hal yang perlu mendapat perhatian serius oleh tenaga kesehatan, baik dokter gigi maupun perawat gigi, hal ini terlihat bahwa penyakit gigi dan mulut masih diderita oleh 90\% penduduk Indonesia (Indrayati Fadjeri, 2016). Menurut WHO (World Health Organization) tahun 2013, di seluruh dunia 60-90 $\%$ dari anak-anak sekolah dan hampir $100 \%$ orang dewasa mengalami karies gigi, yang sering menimbulkan rasa sakit dan ketidaknyamanan (Talibo, Mulyadi, \& Bataha, 2016). Masalah kesehatan gigi dan mulut anak di Indonesia masih sangat rendah, sebanyak $89 \%$ anak di bawah usia 12 tahun menderita masalah kesehatan gigi dan mulut (Patria. Nunik, 2017).

Riskesdas 2013 ditemukan sebagian besar penduduk Indonesia menyikat gigi pada saat mandi pagi maupun mandi sore, $(76,6 \%)$. Menyikat gigi dengan benar adalah setelah makan pagi dan sebelum tidur malam, untuk Indonesia ditemukan hanya 2,3\%. Sedangkan Riskesdas 2018 Proporsi masalah gigi dan mulut serta mendapatkan pelayanan dari tenaga medis gigi menurut provinsi, yaitu di indonesia 57,6\%. Proporsi perilaku menyikat gigi setiap hari pada penduduk indonesia umur > 3 tahun 94,7\%. Proporsi perilaku menyikat gigi dengan benar pada penduduk usia $>3$ tahun di indonesia $2.8 \%$. dan yang di jawa timur proporsi masalah gigi dan mulut serta mendapatkan pelayanan dari tenaga medis gigi menurut provinsi, yaitu $47 \%$. Proporsi perilaku menyikat gigi setiap hari pada penduduk indonesia umur $>3$ tahun 93\%. Proporsi perilaku menyikat gigi dengan benar pada penduduk usia $>3$ tahun $1.9 \%$. prevalensi cara menggosok gigi.

Manfaatnya dari menggosok gigi yaitu untuk membersihkan gigi dari kotoran terutama plak sisa-sisa makanan, mencegah gigi berlubang dan terhindar dari sakit gigi serta menghilangkan bau mulut dan menjaga gigi agar tetap sehat
(Friedman, 2003). rasa sakit pada gigi dan mulut pada anak yang akan menurunkan selera makan pada anak, dampak lainnya adalah kemampuan belajar anak kurang sehingga berpengaruh pada prestasi belajar anak (Pratiwi, 2007). Anak usia dini (3-6 tahun) masih belum memahami dan mengerti cara merawat gigi dengan baik. Kerusakan gigi dapat dicegah dengan cara menggosok gigi sebelum tidur dan sesudah makan (Setiawan \& Maftukhah, 2016).

Upaya untuk meningkatkan cara menggosok gigi pada anak memerlukan metode dan media, yaitu metode stimulasi dan modeling, dalam metode modeling itu dapat menggunakan media, seperti media audiovisual karena mudah dimengerti oleh anak usia prasekolah. Media audiovisual menambah kejelasan anak dan tidak mudah bosan. Anak prasekolah yaitu anak-anak yang berusia antara 3-6 tahun (Biechler, Snowman 1993). awal masa kanak-kanak ini merupakan masa yang ideal untuk mempelajari keterampilan tertentu dan dapat dianggap sebagai "saat belajar" untuk belajar keterampilan (Astutik, 2000). Anak belajar dan diajar oleh lingkungan mengenai bagaimana ia harus bertingkah laku yang baik dan tidak baik, lingkungan dapat berarti orangtua, guru, dan teman-temannya (Santosa, 2011).

Penerapan teknik modeling dapat meningkatkan kemampuan belajar membaca nyaring siswa kelas III SD Terpencil Gondalon (Asrianti et al., 2014). Berdasarkan hasil penelitian Sofwan Adiputra dapat disimpulkan bahwa bimbingan kelompok dengan teknik modeling efektif meningkatkan perencanaan karir siswa kelas X SMA Yasmida Ambarawa Tahun Pelajaran 2013/2014 (Adiputra, 2015). Berdasarkan hasil penelitian Rumiani,dkk dapat disimpulkan bahwa teknik modeling terbukti dapat meningkatkan motivasi belajar siswa kelas VIII 6 SMP Negeri2 Singaraja (Rumiani, Suarni, Arum, \& Metra, 2014). Menurut hasil penelitian Syarifah,dkk terdapat pengaruh stimulasi tentang ginggivitis terhadap pengetahuan anak (Syarifah Nur Laili Siyam, Arlina Nurhapsari, 2015).

Berdasarkan hasil interview terhadap 10 anak TK yang mengalami masalah pada gigi dan mulut, sebagian besar mereka mengatakan bahwa mereka kurang mengerti cara memelihara kesehatan gigi dan cara menggosok gigi yang benar. Mereka mengatakan tidak mau menggosok gigi karena pasta gigi yang digunakan pedas dan pahit. Dan juga terlihat banyak pedagang jajanan di luar sekolah atau pinggir jalan sekolah menjual makanan yang manis-manis. Menurut orang tua 
masing-masing anak, mereka mengatakan bahwa anaknya sering makan makanan yang manismanis tapi tidak mau menggosok gigi. Mereka mengatakan anaknya menggosok gigi waktu mandi pagi saja dan itupun kadang-kadang.

Berdasarkan permasalahan di atas peneliti tertarik untuk melakukan penelitian tentang "Efektifitas metode stimulasi dan metode modeling terhadap cara menggosok gigi di TK Bina Anak Prasa Pondok Pesantren Nurul Jadid Paiton Probolinggo". Adanya metode stimulasi dan modeling pada anak prasekolah (3-6 tahun) di harapkan untuk merubah sikap dan tingkah laku anak dan juga untuk menambah pengetahuan ibu tentang cara mendidik atau mengajarkan menggosok gigi pada anak.

\section{METODE}

Jenis penelitian yang digunakan adalah Quasi Eksperiment dengan pendekatan two group prepost test design. Dan untuk mengetahui perubahan rata-rata sikap dan keterampilan pre-post test responden yaitu menggunakan uji wilcoxon dan mann-whitney. Wilcoxon untuk mengetahui perubahan sebelum dan sesudah diberi penyuluhan, mann-whitney untuk membandingkan 2 variabel atau kelompok, lebih efektif yang mana.

Sampel diambil menggunakan purposive sampling. Jumlah responden yang akan diteliti adalah 80 anak dan sesuai dengan kriteria inklusi. Peneliti membagi siswa menjadi 2 kelompok yaitu 40 kelompok stimulasi dan 40 kelompok modeling. observasi dilakukan sebelum dan sesudah dilakukan penyuluhan. Pengukuran observasi dilakukan melalui lembar observasi.
Penilaian lembar observasi cara menggosok gigi yang benar menetapkan bobot jawaban terhadap tiap-tiap pertanyaan. Dimana terdapat 10 pertanyaan yaitu diantaranya: berkumurkumur dengan air bersih, menggunakan sikat gigi yang berbulu halus, menggosok gigi menggunakan odol, osisi sikat membentuk sudut 45 derajat, kemudian gosok gigi bagian depan anda secara lembut dan perlahan dengan cara memutar, gunakan gerakan yang sama, yaitu memutar untuk menyikat bagian permukaan gigi dalam, gosok semua bagian permukaan gigi yang digunakan untuk mengunyah, yaitu gigi geraham, gosok gigi dengan posisi tegak dan gerakkan perlahan ke atas dan ke bawah untuk membersihkan gigi depan bagian dalam, menggosok bagian bawah gigi dengan gerakan maju mundur, menyikat lidah setelah selesai menggosok gigi dapat membersihkan bakteri sehingga napas lebih segar dan terhindar dari bau mulut, bilas dengan cara berkumur menggunakan air lakukan dirasa sampai cukup bersih.

Adapun kriteria inklusi: anak prasekolah usia 3 - 6 tahun, anak yang kooperatif, orangtua yang mau mengisi Informed Consent. Kriteria eksklusi : anak yang sudah mendapatkan pelatihan cara menggosok gigi, siswa yang tidak mempunyai gigi. Data dianalisis menggunakan distribusi frekuensi dan uji Wilcoxon.

\section{HASIL}

Hasil penelitian dapat dilihat pada tabel berikut.

Tabel 1.

Karakteristik responden berdasarkan umur

\begin{tabular}{lcccc}
\hline Umur & \multicolumn{5}{c}{ Kelompok intervensi stimulasi $(\mathrm{n}=40)$} & \multicolumn{1}{c}{ Kelompok intervensi modeling $(\mathrm{n}=40)$} \\
\cline { 2 - 5 } & $\mathrm{f}$ & $\%$ & $\mathrm{f}$ & $\%$ \\
\hline 3 thn & 0 & 0 & 0 & 0 \\
4 thn & 39 & 97,5 & 0 & 0 \\
5 thn & 1 & 2,5 & 36 & 10 \\
6 thn & 0 & 0 & 4 & kelompok intervensi modeling mayoritas usia 5 \\
Tabel 1 menunjukkan bahwa mayoritas responden & tahun. \\
pada kelompok stimulasi usia 4 tahun dan &
\end{tabular}

Tabel 2.

Karakteristik responden berdasarkan kelas

\begin{tabular}{|lcccc|}
\hline Kelas & \multicolumn{3}{c|}{ Kelompok intervensi stimulasi $(\mathrm{n}=40)$} & Kelompok intervensi modeling $(\mathrm{n}=40)$ \\
\cline { 2 - 5 } & $\mathrm{f}$ & $\%$ & $\mathrm{f}$ & $\%$ \\
$\mathrm{~A}(1.2)$ & 40 & 100 & 0 & 0 \\
$\mathrm{~B}(1.2)$ & 0 & 0 & 40 & 100 \\
\hline
\end{tabular}


Tabel 2. Menunjukkan responden pada kelompok sebanyak 40 responden intervensi stimulasi dan modeling, masing-masing

Tabel 3.

Karakteristik responden berdasarkan jenis kelamin $(\mathrm{n}=80)$

\begin{tabular}{lcc}
\hline Jenis kelamin & $\mathrm{f}$ & $\%$ \\
\hline Laki-laki & 38 & 47,5 \\
Perempuan & 42 & 52,5 \\
\hline
\end{tabular}

Tabel 3 menunjukkan bahwa karakteristik responden mayoritas berjenis kelamin perempuan.

Tabel 4.

Cara menggosok gigi yang benar pada anak prasekolah sebelum dan sesudah penyuluhan pada kelompok intervensi stimulasi (visual learning)

\begin{tabular}{l|c|c|c|c}
\hline \multirow{2}{*}{$\begin{array}{c}\text { Kriteria menggosok gigi } \\
\text { yang benar }\end{array}$} & \multicolumn{2}{|c|}{ Sebelum } & \multicolumn{2}{c}{ Sesudah } \\
\cline { 2 - 5 } & $\mathrm{f}$ & $\%$ & $\mathrm{f}$ & $\%$ \\
\hline Benar & 0 & 0 & 15 & 37,5 \\
Salah & 40 & 100 & 25 & 62,5 \\
\hline
\end{tabular}

Tabel 4 menunjukkan bahwa sebelum penyuluhan kebersihan gigi dan mulut dengan visual learning di dapatkan nilai terbanyak pada kriteria salah

sejumlah 40 responden (100\%). Setelah dilakukan penyuluhan didapatkan mayoritas nilai dengan kriteria salah sejumlah 25 responden $(62,5 \%)$.

Tabel 5.

Hasil Uji Statistik Wilcoxon saat sebelum dan sesudah penyuluhan pada kelompok intervensi stimulasi (visual learning) $(\mathrm{n}=40)$

\begin{tabular}{crrc}
\hline Kelompok Intervensi & Mean Rank & Sum of Rank & P Value \\
\hline Sebelum & 12.62 & 50.50 & 0.000 \\
Sesudah & 18.69 & 579.50 & \\
\hline
\end{tabular}

Tabel 5 menunjukkan bahwa sebelum dengan nilai peringkat rata-rata 12.62 dan setelah dilakukan penyuluhan pendidikan kesehatan mempunyai nilai peringkat rata-rata 18.69 . Hasil uji statistik Wilcoxon didapatkan nilai $\rho=0,000$

Tabel 6.

Distribusi cara menggosok gigi yang benar pada anak prasekolah sebelum dan sesudah penyuluhan pada kelompok intervensi modeling (live model) $(\mathrm{n}=40)$

\begin{tabular}{l|c|c|c|c}
\hline \multirow{2}{*}{$\begin{array}{l}\text { Kriteria menggosok } \\
\text { gigi yang benar }\end{array}$} & \multicolumn{2}{|c|}{ Sebelum } & f & $\%$ \\
\cline { 2 - 5 } & $\mathrm{f}$ & $\%$ & 37 & 92,5 \\
Benar & 0 & 0 & 3 & 7,5 \\
\hline
\end{tabular}

Tabel 6 menunjukkan bahwa sebelum penyuluhan kebersihan dan kesehatan gigi dan mulut dengan live model di dapatkan nilai terbanyak pada kriteria salah sejumlah 40 responden $(100 \%)$.

Tabel 7. Hasil Uji Statistik Wilcoxon sebelum dan sesudah penyuluhan pada kelompok intervensi modeling (live model) di TK Bina Ana Prasa PP Nurul Jadid

\begin{tabular}{cccc}
\hline Kelompok Intervensi & Mean Rank & Sum of Rank & P Value \\
\hline Sebelum & 0.00 & 0.00 & 0.000 \\
Sesudah & 20.50 & 820.00 & \\
\hline
\end{tabular}

Tabel 7 menunjukkan bahwa hasil uji statistik Wilcoxon didapatkan nilai $\rho=0,000$ dan $\alpha=0,05$

artinya $\rho<\alpha$, sehingga $\mathrm{H} 0$ ditolak dan $\mathrm{Ha}$ terbanyak pada kriteria benar sejumlah 37 responden $(92,5 \%)$ dan $\alpha=0,05$ artinya $\rho<\alpha$, sehingga H0 ditolak dan Ha diterima, yang berarti ada pengaruh penyuluhan cara menggosok gigi yang benar pada kelompok intervensi Stimulasi. diterima, yang berarti ada pengaruh penyuluhan cara menggosok gigi yang benar pada kelompok intervensi Modeling (live model). 
Tabel 8.

Hasil Uji Statistik Mann-Whitney saat dilakukan penyuluhan dengan metode stimulasi dan modeling pada kelompok intervensi

\begin{tabular}{llll}
\hline Metode & Mean Rank & Sum of Rank & P Value \\
\hline Stimulasi & 28.21 & 2111.50 & 0.000 \\
Modeling & 52.79 & 1128.50 & \\
\hline
\end{tabular}

Tabel 8 menunjukkan bahwa hasil $\rho=0,000$ dan $\alpha=0,05$ artinya $\rho<\alpha$, sehingga dapat di simpulkan ada perbedaan perilaku dengan menggunakan metode Stimulasi dan Modeling.

\section{PEMBAHASAN}

Analisis cara menggosok gigi yang benar pada anak prasekolah sebelum dan sesudah penyuluhan pada kelompok ekperimen stimulasi

Berdasarkan penelitian yang di lakukan di TK Bina Ana Prasa PP Nrul Jadid paiton probolinggo pada tanggal 25 januari-10 februari 2019 dengan menggunakan uji statistik Wilcoxon di dapatkan bahwa pada kelompok eksperimen stimulasisebelum di berikan penyuluhan cara menggosok gigi yang benar mempunyai nilai ratrata 12,62 dan setelah dilakukan penyuluhan cara menggsok gigi yang benar mempunyai nilai ratarata 18,69 juga di dapatkan nilai signifikan $0,000(\mathrm{Z}=-4.365)$ dengan nilai $\rho=0,000$ dan $\alpha=$ 0,05 artinya $\rho<\alpha$, sehingga $\mathrm{H} 0$ ditolak dan $\mathrm{Ha}$ diterima, yang berarti ada pengaruh penyuluhan cara menggosok gigi yang benar pada kelompok intervensi stimulasi (visual learning) .Dengan demikian dalam proses belajar mengajar di perlukan media yang menarik agar anak cepat memahami dan tidak bosan. Sebelum dilakukan penyuluhan anak-anak masih belum tahu bagaimana cara menggosok gigi yang benar, meraka menggosok gigi hanya dengan setahunya mereka entah itu benar atau salah,anak yang salah dalam menggosok gigi sejumlah 40 responden $(100 \%)$ dan yang benar sejumlah 0 responden $(0 \%)$. setelah dilakukan penyuluhan dengan menggunakan vidio anak bisa melihat bagaimana cara menggosok gigi yang benar. Dalam vidio peneliti menggunakan gambar kartun agar anak lebihtertarik untuk melihatnya. Dan anak yang benar dalam menggosok gigi sejumlah 15 responden $(37,5 \%)$. dan yang salah sejumlah 25 responden $(62,5 \%)$, sehingga dapat dikatakan terdapat peningkatan perubahan perilaku pada anak prasekolah dengan metode stimulasi.

Hasi penelitian sebelumnya yang dilakukan oleh Syarifah, dkk (2015), pada anak usia 8-11 tahun. Terdapat perubahan rata-rata pengetahuan anak tentang gingivitis pada usia 8-11 tahun sebelum dan sesudah diberikan penyuluhan dengan metode stimulasi (Syarifah Nur Laili Siyam, Arlina Nurhapsari, 2015). Uraian tersebut peneliti dapat menyimpulkan bahwa ada pengaruh stimulasipermainan ular tangga tentang gingivitis terhadap pengetahuan anak usia 8-11 tahun serta terdapat perubahan rata-rata pengetahuan anak tentang gingivitis pada usia 8-11 tahun sebelum dan sesudah diberikan penyuluhan dengan metode stimulasi permainan ular tangga (Syarifah Nur Laili Siyam, Arlina Nurhapsari, 2015).

Peneliti sebelumnya juga dilakukan oleh Febrina,dkk (2016) yang berjudul "Pengaruh Pemberian Stimulasi pada Perkembangan Anak Usia 12-36 Bulan di Kecamatan Sedayu, Bantul"dengan hasil penelitian terdapat hubungan positif kuat dan secara statistik signifikan antara stimulasi tumbuh kembang dengan perkembangan anak usia 1-3 tahun di Kecamatan Sedayu ( $\mathrm{p}=$ 0,001 ; CI 95\%; $\rho=0,682$ ) (Febrina Suci Hati, 2016).

Stimulasi adalah kegiatan merangsang kemampuan dasar anak agar anak dapat tumbuh dan berkembang secara optimal.Setiap anak perlu mendapatkan stimulasi rutin sedini mungkin dan terus menerus pada setiap kesempatan. Stimulasi ini dapat dilakukan oleh ibu dan ayah yang merupakan orang terdekat, pengganti $\mathrm{ibu} /$ pengasuh anak, anggota keluarga lain dan kelompok masayarakat di lingkungan rumah tangga masing-masing dan dalam kehidupan sehari-hari(Yuli Yusuf, Sefty Rompas, 2016). Mengingat stimulasi merupakan faktor yang sangat penting dalam mendukung perkembangan anak bilamana dilakukan secara benar.Kelebihan dari metode stimulasi (visual learning) atau video sangat berguna untuk mendemonstrasikan keterampilan pikiran. Selain itu, observer juga dapat mengamati pesan-pesan tubuh dari rekaman tersebut. Kelemahan model ini adalah perlu didengarkan atau dilihat berulang-ulang. Selain itu, rekaman audio atau video tidak sespontan model langsung(Ni Putu Vivin Indrawati, Ni Ketut Suarni, 2016). 


\section{Analisis cara menggosok gigi yang benar pada anak prasekolah sebelum dan sesudah penyuluhan pada kelompok ekperimen modeling}

Berdasarkan penelitian yang di lakukan di TK Bina Ana Prasa PP Nrul Jadid paiton probolinggo pada tanggal 25 januari-10 februari 2019 dengan menggunakan uji statistik Wilcoxon di dapatkan bahwa pada kelompok eksperimenmodeling sebelum di berikan penyuluhan cara menggosok gigi yang benar mempunyai nilai rat-rata 0.00 dan setelah dilakukan penyuluhan cara menggsok gigi yang benar mempunyai nilai rata-rata 20.50 juga di dapatkan nilai signifikan $0,000(Z=-5.538)$ dengan nilai $\rho=0,000$ dan $\alpha=0,05$ artinya $\rho<\alpha$,sehingga $\mathrm{H} 0$ ditolak dan Ha diterima, yang berarti ada pengaruh penyuluhan cara menggosok gigi yang benar pada kelompok intervensimodeling (live model).

Sebelum dilakukan penyuluhan anak-anak masih belum tahu bagaimana cara menggosok gigi yang benar, meraka menggosok gigi hanya dengan setahunya mereka entah itu benar atau salah, anak yang salah dalam menggosok gigi sejumlah 40 responden $(100 \%)$ dan nilai terendah pada kriteria benar sejumlah 0 responden $(0 \%)$. setelah dilakukan penyuluhan dengan menggunakan pantum gigi anak bisa melihat bagaimana cara menggosok gigi yang benar, dan bisa mencobanya atau memperagakan kembali yang sudah diajarkan. Dan anak yang benar dalam menggosok gigi sejumlah 37 responden $(92,5 \%)$, dan yang salah 3 responden $(7,5 \%)$ sehingga dapat dikatakan terdapat peningkatan perubahan perilaku pada anak prasekolah dengan metode modeling. Hasil penelitian sebelumnya yang dilakukan oleh Nur Asrianti,dkk (2014) Penerapan teknik modeling pada siswa kelas III SD ternyata adapengaruhterhadap kemampuan belajar membaca nyaring siswa kelas III SD Terpencil Gondalon (Asrianti, Tahir, \& Barasandji, 2014).

Penelitian sebelumnya juga dilakukan oleh Vivin Indrawati,dkk (2016) yang berjudul "Implementasi Teknik Modeling Untuk Meningkatkan Kemampuan Berbicara Pada Anak Kelompok B1" implementasi tehnik modeling sangat efektif untuk meningkatkan kemampuan berbicara pada anak kelompok B1 di TK Ganesha Singaraja Semester II Tahun Pelajaran 2015/2016. Hal ini dapat dilihat rata-rata kemampuan berbicara pada siklus I sebesar 63,33\% dengan kategori rendah dan mengalami peningkatan mencapai $82,53 \%$ dengan kategori tinggi pada siklus II. Dengan demikian terjadi peningkatan kemampuan berbicara pada anak melalui implementasi teknik modeling sebesar 19,20\%. Jadi berdasarkan kriteria keberhasilan yang telah ditetapkan, maka pelaksanaan tindakan ini secara keseluruhan dapat dikatakan berhasil karena adanya peningkatan dari siklus I pada katagori rendah menjadi tinggi pada siklus $\mathrm{II}(\mathrm{Ni}$ Putu Vivin Indrawati, Ni Ketut Suarni, 2016).

Penelitian sebelumnya juga dilakukan oleh Dwi Srihartini (2012) dengan judul "Peningkatan Keterampilan Membaca Puisi Melalui Metode Modeling Pada Siswa Kelas II SDN 2 Tegowanu Kulon Kecamatan Tegowanu Kabupaten Grobogan"Hasil penelitian melalui metode modeling dalam pembelajaran membaca puisi dapat meningkatkan keterampilan membaca puisi siswa kelas II SDN 2 Tegowanu Kulon Kecamatan Tegowanu Kabupaten Grobogan (Srihartini, 2012).

Istilah modeling merupakan istilah umum untuk menunjukkan terjadinya proses belajar melalui pengamatan dari orang lain dan perubahan yang terjadi karenanya melalui peniruan. Modeling berakar dari teori Albert Bandura yang telah dimulai tahun 50-an, meliputi tokoh nyata, tokoh melalui film, dan tokoh imajinasi. Teknik modeling ini dibagi menjadi tiga yaitu lives model, symbolic models, dan multiple models. Bandura mengatakan bahwa modeling merupakan, "sebuah teknik belajar yang dilakukan dengan mengamati tingkah laku model secara langsung maupun tidak langsung". Belajar melalui pengalaman tidak langsung, yaitu dengan mengamati tingkah laku orang lain(Ni Putu Vivin Indrawati, Ni Ketut Suarni, 2016).

\section{Analisis Pengaruh metode stimulasi dan modeling terhadap cara menggosok gigi yang benar pada anak prasekolah di TK Bina Ana Prasa PP Nurul Jadid}

Penelitian yang di lakukan di TK Bina Ana Prasa PP Nrul Jadid paiton probolinggo pada tanggal 25 januari-10 februari 2019 dengan menggunakan uji statistik Mann-Whitney pada kelompok intervensi stimulasi dan modeling menunjukkan nilai $\mathrm{P}$ value $0.000 \alpha=0,05$ artinya $\rho<\alpha$, dan itu berarti adalah terdapat perbedaan antara yang stimulasi dan modeling. Salah satu upaya meningkatkan keterampilan anak adalah melaluipenyuluhan kebersihan gigi dan mulut yang hasilnya diharapkan dapatmerubah keterampilan anak menjadi lebih baik, keberhasilan suatupenyuluhan kebersihan gigi dan mulut juga tidak lepas dari peran sebuahmedia yang sesuai dengan sasaran responden yang akan diteliti. Dalampenelitian ini 
peneliti menggunakan metode penyuluhan kebersihan gigi dan mulut yangdigunakan adalah metode Stimulasi dan metode modeling.MetodeStimulasi adalah metode merangsang anak melalui video.Pesatnya perkembangan teknologi saat ini menuntut kita agar tanggap dengan segala sesuatu yang berhubungan dengan teknologi canggih sebagai alat untuk menampilkan video seperti laptop dan LCD. Sedangkan pada metode modeling responden dikasih penyuluhan dengan peragaan secara langsung yang dilakukan secara langsung dengan responden.Pada metode modeling alat bantu yang digunakan adalah pantom gigi, dimana pantom gigi merupakan alat bantu yang digunakan sebagai contoh dalam melakukan penyuluhan kebersihan gigi dan mulut. Dari hasil penelitian ini didapatkan bahwa ada pengaruh penyuluhan dengan metode stimulasi dan modeling terhadap cara menggosok gigi yang benar pada anak prasekolah di TK Bina Ana Prasa PP Nurul Jadid.

Hasil penelitian sebelumnya dilakukan oleh Nazarwin Saputra (2011) dengan judul "Perbedaan Pengaruh Pendidikan Kesehatan HIV/AIDS Dengan Metode Curah Pendapat dan Stimulasi (audio visual) Terhadap Pengetahuan Siswa SMAN 4 Tengerang Selatan" bahwa ada perbedaan pengetahuan yang bermakna antara sebelum dan sesudah intervensi pendidikan kesehatan HIV/AIDS pada kelompok siswa yang mendapatkan intervensi pendidikan kesehatan HIV/AIDS dengan metode curah pendapat yaitu $\mathrm{P}$ Value $=0,000$. Dan pada kelompok siswa yang mendapatkan intervensi pendidikan kesehatan HIV/AIDS dengan metode stimulasi (audio visual) yaitu $P$ Value $=0,000$, yang artinya tidak ada perbedaan pengaruh pendidikan kesehatan HIV/AIDS dengan metode curah pendapat dan stimulasi (audio visual) siswa SMAN 4 tengerang selatan dengan nilai $\mathrm{P}$ Value $=0,566$. Sedangkan nilai efektivitas kelompok curah pendapat adalah $100 \%$. Sedangkan jumlah responden yang mengalami peningkatan pengetahuan pada kelompok stimulasi (audio visual) sebanyak 15 responden, maka nilai efektivitas pada kelompok ini adalah 93,75\%. Dengan demikian selisih efektivitas metode curah pendapat dan simulasi (audio visual) adalah 6,25\%. Yang artinya lebih efektif yang curah pendapat (Saputra, 2011).

\section{SIMPULAN}

Metode stimulasi dan modeling dapat meningkatkan perilaku dan keterampilan anak untuk menggosok gigi yang benar. Dan dari hasil observasi stimulasi dan modeling itu lebih efektif yang modeling.

\section{DAFTAR PUSTAKA}

Adiputra, S. (2015). Penggunaan Teknik Modeling Terhadap Perencanaan Karir Siswa, Jurnal Fokus Konseling Volume 1. (1), 45-56.

Asrianti, N., Tahir, M., \& Barasandji, S. (2014). Peningkatan Kemampuan Siswa Membaca Nyaring Melalui Teknik Modeling di Kelas III SD Terpencil Gondalon, Jurnal Fokus Konseling. 4(6), 158-172.

Astutik. (2000). Peran Orang Tua Terhadap Perkeit'ba],Igan Anak Usia Prasekolah, jurnal keperawatan.

Biechler dan Snowman. \& S. (1993). Perkembangan Anak. PT. Remaja Rosdakarya. Bandung.

Indrayati Fadjeri, J. K. (2016). Hubungan Perilaku Kesehatan Ibu Dengan Status Kebersihan Gigi Dan Mulut Anak Usia Dibawah 5 Tahun Di Perumahan Bumi Sawangan Indah Sawangan Depok. Dosen Poltekkes Kemenkes Jakarta I.

Larasati, R. (2013). Hubungan Kebersihan Mulut dengan Penyakit Sistemik dan Usia Harapam Hidup. Jurnal Skala Husada, 9(1), 97-104.

Ni Putu Vivin Indrawati, Ni Ketut Suarni, P. R. U. (2016). Implementasi Teknik Modeling Untuk Meningkatkan Kemampuan Berbicara Pada Anak Kelompok B1, 4(2).

patria. nunik. (2017). Hubungan Tingkat Pengetahuan Ibu Dengan Perilaku Ibu Dalam Mendidik Anak Menggosok Gigi, Journal Keperawatan. 812-821.

Pratiwi. Gigi Sehat. Penerbit Kompas Media Nusantara. 2007

Riskesdas, 2018, badan penelitian dan pengembangan kesehatan, kementerian kesehatan RI

Roosihermiatie, B., Tumaji, \& Oktarina. (2016). Korelasi Faktor Ibu Dengan Status Kesehatan Gigi Dan Mulut Anak Taman Kanak-Kanak Di Kelurahan Kemayoran Kecamatan Krembangan, Kota Surabaya 
Buletin Penelitian Sistem Kesehatan - Vol. 19(17), 226-235.

Rumiani, N. W., Suarni, N. K., Arum, D., \& Metra, W. (2014). Melalui Konseling Kelompok Untuk Meningkatkan Motivasi Belajar Siswa Kelas Viii 6 Smpn 2 Singaraja Tahun Pelajaran 2013 / 2014 Universitas Pendidikan Ganesha. Ejournal Undiksha Jurusan Bimbingan Konseling Volume 1

Santosa, E. P. H. S. A. B. (2011). Hubungan Peran Orang Tua Dengan Kebiasaan Mencuci Tangan Pada Anak Prasekolah Di Taman Kanak-Kanak Siwi Peni Guntur Demak, jurnal keperawatan 4(2), 106-120.

Saputra, N. (2011). Perbedaan Pengaruh Pendidikan Kesehatan Hiv/Aids Dengan Metode Curah Pendapat Dan Menggunakan Media Audio Visual Terhadap Pengetahuan Siswa Sman 4 Tangerang Selatan.

Setiawan, F., \& Maftukhah, A. (2016). Pengetahuan Ibu Tentang Menggosok Gigi, jurnal AKP 7(1), 30-35.

Srihartini, D. (2012). Peningkatan Keterampilan Membaca Puisi Melalui Metode Modeling Pada Siswa Kelas II SDN 2 Tegowanu Kulon Kecamatan Tegowanu Kabupaten Grobogan.

Syarifah Nur Laili Siyam, Arlina Nurhapsari, B. B. (2015). Pengaruh Stimulasi Permainan Ular Tangga Tentang Gingivitis Terhadap Pengetahuan Anak Usia 8-11 Tahun, ODONTO Dental Journal. Volume 2, 2528.

Talibo, R. S., Mulyadi, M., \& Bataha, Y. (2016). Hubungan Frekuensi konsumsi Makanan Kariogenik dan Kebiasaan Menggosok Gigi Dengan Kejadian Karies Gigi Pada Siswa Kelas III SDN 1 \& 2 Sonuo. E-Journal Keperawatan, 4.

Triska, Damajanti H C, D. (2014). Hubungan Tingkat Pengetahuan Orang Tua Dengan Kebersihan Gigi dan Mulut Anak di TK Tunas Bhakti Manado. Jurnal E-GiGi (eG), Volume 2, Nomor 2, 2, 7-10.

Friedman, M. . (2003). family nursing : reseacrh, theory and practice.
Febrina Suci Hati, P. L. (2016). Pengaruh Pemberian Stimulasi pada Perkembangan Anak Usia 12-36 Bulan di Kecamatan Sedayu, Bantul, 4(1), 44-48.

Yuli Yusuf, Sefty Rompas, A. B. (2016). Pengaruh Pendidikan Kesehatan Dengan Pendekatan Modelling Terhadap Pengetahuan Ibu Dalam Menstimulasi Tumbuh Kembang Bayi 0-6 Bulan Di Posyandu Wilayah Kerja Puskesmas Tomalou Kota Tidore Kepulauan, 4. 